\title{
Remote sensing object-oriented approaches coupled with ecological informatics to map invasive plant species
}

\author{
Sanjay Gairola ${ }^{\mathrm{a}^{*}}$, Şerban Procheş ${ }^{\mathrm{a}}$, Michael Gebreslasie ${ }^{\mathrm{a}}$, and Duccio Rocchini ${ }^{\mathrm{b}}$
}

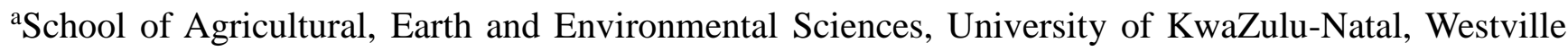
campus, Durban, 4000, South Africa

${ }^{\mathrm{b}}$ Fondazione Edmund Mach, Research and Innovation Centre, Department of Biodiversity and Molecular Ecology, GIS and Remote Sensing Unit, 38010, S. Michele all'Adige, TN, Italy

Corresponding authors email: $\underline{\text { drsanjaygairola@gmail.com }}$

http://dx.doi.org/10.4314/sajg.v5i3.2

\begin{abstract}
Invasive alien plants are considered one of the major threats to biodiversity conservation worldwide. Hence, understanding their distribution and abundance is important in order to assess the impact on native ecosystems. It is particularly important to be able to track the spread of invasive species across landscapes; a task best achieved using remotely sensed imagery. The availability of high resolution data, combined with efficient classification methods, can potentially improve early detection of invasive alien species thereby enhancing their management. This study aims to classify woody species with a focus on Melia azedarach (Meliaceae) trees in a moderately invaded coastal belt valley on the east coast of South Africa using WorldView-2 (WV-2) satellite imagery, and to compare the commonly used pixel-based classification with object-oriented approaches. The results show that object-oriented approaches are more suitable for classifying woody species, as well as other land cover classes when using high-resolution WV-2 imagery. The overall accuracy was $90 \%$ by objectoriented classification, while the pixel-based classification gave an overall accuracy of 78\%. For Melia, a producer accuracy of $92 \%$ and user accuracy of $91 \%$ was obtained by object-oriented classification and a producer accuracy of $85 \%$ and user accuracy of $83 \%$ was obtained by pixel-based classification. Hence the combined use of new generation sensor imagery and the employment of object-oriented image classification techniques provided more accurate information on Melia invasion in the study area. This is an encouraging result given the high degree of intermingling of Melia with other plants at the study site. In particular, the vegetation maps produced from this study would aid in gathering accurate knowledge about the distribution and spreading status of Melia, a major invasive species over large areas of South Africa and elsewhere in the world.
\end{abstract}




\section{Introduction}

Invasive plant species are now viewed as a significant component of global change with impacts across multiple scales, and have become a serious threat to natural communities (Huang and Asner, 2009; Pyšek and Richardson, 2010; He et al. 2011). They can profoundly modify the structure and function of invaded ecosystems, alter biotic interactions, and homogenize diverse plant and animal communities at large spatial scales, ultimately resulting in a loss of genetic, species and ecosystem diversity (Qian and Ricklefs, 2006).

Climate change is likely to enhance the capability of alien species to invade new areas, by simultaneously decreasing the resistance to invasion of natural communities and by disturbing the dynamic equilibrium maintaining them (Thuiller et al. 2007). Understanding the distribution of invasive non-native species is essential for gaining insights into the dynamics of ecosystem-level invasion, formulating effective conservation policies, and developing control measures (Bradley and Mustard, 2006). The spatial mapping by remote sensing tools of invasive plant species at fine scales should inform predictions about future population densities to provide insights into the mechanisms that facilitate invasion (Wilfong et al. 2009). With recent developments in spatial and spectral resolution, and more advanced data processing techniques, detailed classification maps for vegetation communities and individual species can be produced to provide a better source of information for a variety of management decisions and ecological applications (Arenas-Castro et al. 2013). These advances in remote sensing and processing techniques have opened up new opportunities for the development of operational mapping and monitoring of small features such as individual tree crowns (Levin et al. 2007, Rocchini, 2007, Stow et al. 2008, Peerbhay et al. 2016). Promising results have been obtained elsewhere on tree species mapping with WorldView-2 data (Omar, 2010; Immitzer et al. 2012). However, mapping tree species by remotely-sensed imagery is a difficult task because of the high spectral variation within species (Lucas et al. 2008). Some researchers proposed various approaches using recent very high spatial resolution satellite data e.g. (He et al. 2011; Laba et al. 2008). Current and accurate maps of woody species using remote sensing techniques could provide useful information on the spatial distribution of invasive species occurrence, before they become problematic (Hantson et al. 2012).

Object-based image analysis of high-resolution imagery has been successfully used for vegetation mapping and such methods have obtained better classification results than with a traditional pixelbased classification for mapping invasive woody species (Hantson et al. 2012). Laliberte et al. (2004) used this method specifically for shrub encroachment mapping over time, and Smith et al. (2008) studied the process of juniper encroachment over a period of 59 years. (Hantson et al. 2012) study revealed that the object-based classification increase the classification accuracy by $25 \%$ and delivers detailed maps of the woody species that are useful for management and evaluation of alien and invasive species in dune ecosystems. 
It is a well-established fact that invasive plant species are causing severe environmental and ecological impacts. As an example, the spread of non-native plant species, especially those capable of rapid invasion, is already causing considerable negative impacts on the biodiversity and functioning of ecosystems in South Africa. Tree invasions have been well documented in South Africa, where they have resulted in major ecosystem alterations, particularly in areas that did not have an indigenous tree flora, such as grasslands and the species hyper-rich Cape fynbos (Rundel et al. 2014). In many of these cases, the invaders are pines and gums (Pinaceae: Pinus; Myrtaceae: Eucalyptus), both of which have been extensively studied country-wide (Procheş et al. 2012; Richardson et al. 2014). Nevertheless, there are a number of other woody invaders in the country, receiving comparatively little attention. Melia azedarach (Meliaceae) hereafter 'Melia' (and locally, but incorrectly known as 'syringa'), is one of the most serious alien invasive tree species, with rapid colonising ability that has been linked to its dispersal by indigenous birds and bats (Voigt et al., 2011). Melia has been listed as one of the most invasive plants in South Africa and the savanna biome is the most extensively invaded by this species (Thuiller et al. 2006). Originating from southern Asia and Australia, Melia was introduced to North and South America, the Mediterranean Basin and Africa (Voigt et al. 2011). In some of the savanna and biome mosaic areas, this species is taking over areas originally occupied by native vegetation, and could become the dominant species in a new emerging vegetation type in near future. To the best of our knowledge, there is no information available on the use of remote sensing in mapping Melia in South Africa. Therefore, the present study was carried out to evaluate the potential of using WorldView-2 (WV-2) satellite imagery through supervised classification (maximum likelihood) and object-oriented classification for discriminating and mapping woody species, with a special focus on Melia in a study area located within the eThekwini (Durban) Municipality, South Africa. The aim of this paper was to address two key questions: (1) can the use of object-oriented increase the accuracy of the woody species detection? And (2) can remote sensing-based methods deliver information on specific invasive alien woody species that is useful for monitoring and management?

\section{Materials \& Methods}

\subsection{Study area}

The study area is the valley of the Mbongokazi stream, a tributary of the Palmiet River, which is in turn a tributary of the Umgeni River, the largest water course in Durban, South Africa (Figure 1). 


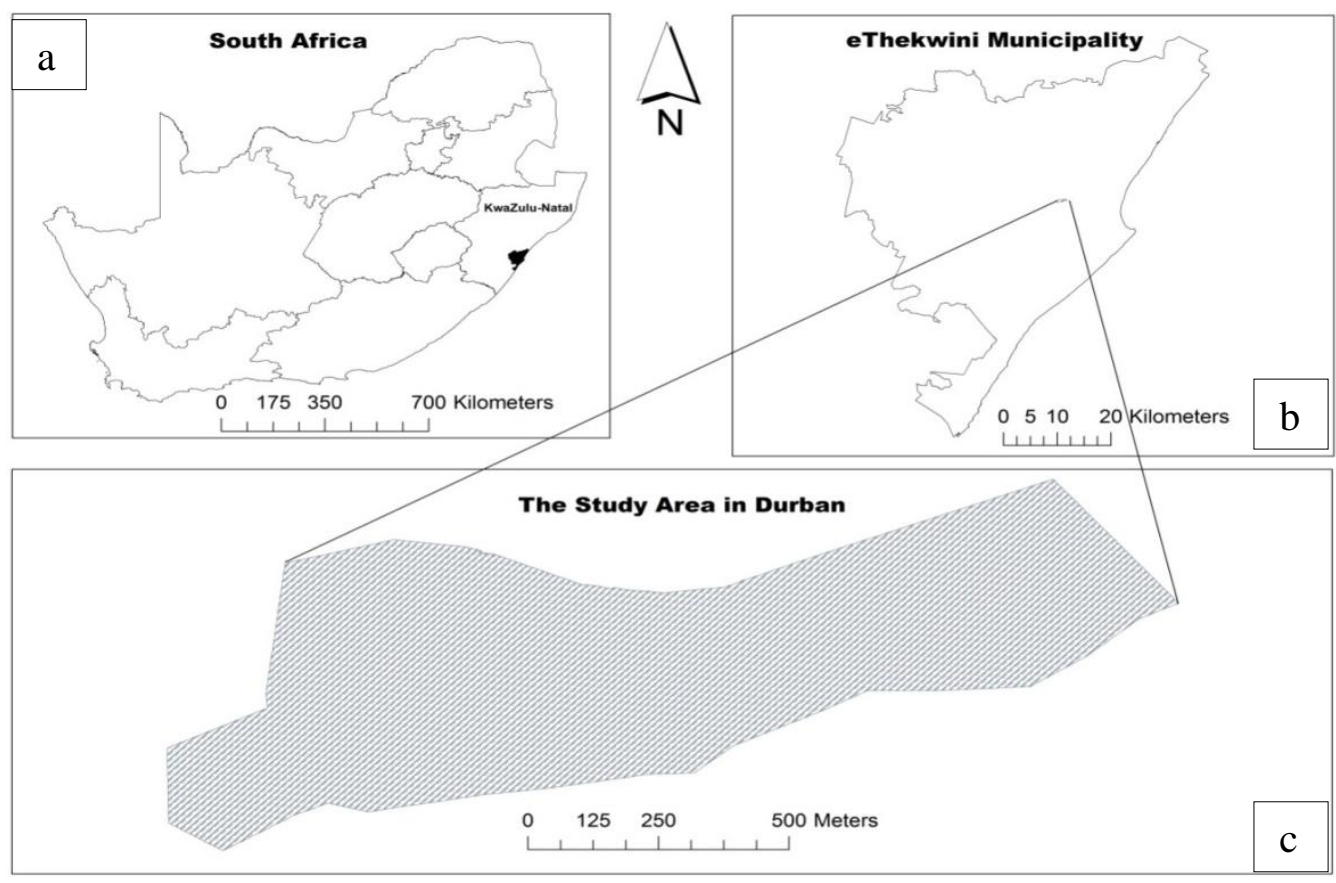

Figure 1. Map of the study area, (a) South Africa (b) eThekwini Municipality (c) the valley of the Mbongokazi stream, in Westville.

The valley covers approximately 66 hectare and is located in the Westville North area of Durban,

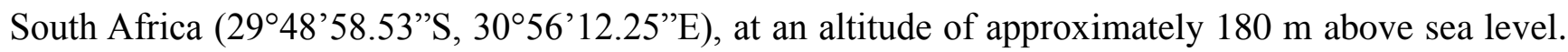
The valley contains coastal valley forest grading into thicket and (on the ridges, which fall outside the study area considered here) into savanna and grassland. Some of the indigenous overstorey woody species are Albizia adianthifolia, Acacia robusta, Acacia sieberiana, Acacia nilotica, Bridelia micrantha, Dalbergia armata, Dalbergia obovata, Clerodendron glabrum, Combretum molle, Croton sylvaticus, Cussonia spicata, Rhus chirindensis, Faurea saligna, Ficus capensis, Ficus natalensis, Heteropyxis natalensis, Hippobromus pauciflorus, Protorhus longifolia, Sclerocarya birrea, and Zizyphus macronata. Alien tree species that are either invasive or locally naturalised include Jacaranda mimosifolia, Litsea glutinosa, Mangifera indica, Melia azedarach, Morus alba and Tecoma stans. While some tree species occur in clusters, most are interspersed among individuals of other species, creating a heterogeneous top layer in the vegetation. The area is challenging to analyse due to overlapping tree crowns which seems to modify the vegetation's spectral signatures.

\subsection{Remotely sensed image}

One cloud-free WV-2 scene acquired on 09 October 2011 was obtained from the South African Remote Sensing Agency at no cost. WV-2 data is characterized by high spatial resolution in a panchromatic (with a spatial resolution of $0.5 \mathrm{~m}$ ) and eight multispectral (with spatial resolution of 2 m) bands, and Radiometric resolution of 2048 (i.e. 11-bit digital numbers (DN)). It has an average revisit time of 1.1 days with a swath width of $16.4 \mathrm{~km}$ at nadir. The target species (Melia) flowers 
mainly in the October which coincides with the cloud-free condition in the study area; in winter it is leafless, exposing the bare ground underneath. So the selection of an early October image was made taking these points into consideration. To meet the study's goals, the WV-2 imagery was pre-processed to at-sensor radiance values, and to geometrically correct. The image was converted from DN to atsensor radiance values $\left(\mu \mathrm{W} \mathrm{cm}{ }^{-1} \mathrm{sr}^{-1} \mathrm{~nm}^{-1}\right)$ through ENVI service Pack 2. The geo-rectification of the WV-2 image was verified using ground control points. The study area has relatively flat terrain, so a second-order polynomial method was chosen to geometrically correct the image, and the nearest neighbour was selected as a resampling method. A total of 45 ground control points were collected using a Trimble JUNO ${ }^{\mathrm{TM}}$ GPS device throughout the study area for this purpose, and a root-meansquare error of 0.41 pixels was obtained.

A panchromatic band with $0.5 \mathrm{~m}$ spatial resolution and eight multispectral bands with $2 \mathrm{~m}$ spatial resolution were fused through an Intensity, Hue, and Saturation (IHS) transformation with a band 4 $(0.59 \mu \mathrm{m}-0.63 \mu \mathrm{m})$, band $3(0.51 \mu-0.58 \mu \mathrm{m})$, and band $2(0.45-0.51 \mu \mathrm{m})$ combination for RGB colour. The HIS fusion method converts a colour image from the red, green and blue (RGB) space into the IHS space. The intensity band in the IHS space is replaced by a high resolution pan image and then transformed back into the original RGB space. A fused pan-sharpened image was then used for objectoriented image analysis (OBIA) classification, while the eight multispectral bands were used for maximum likelihood classification. Object-oriented classification performs well at high spatial resolution, while pixel-based classification works better at intermediate spatial resolution (Bernabé et al. 2014). Consequently, we used different resolutions for the object-oriented classification and pixelbased classification $(0.5 \mathrm{~m}$ and $2 \mathrm{~m}$ respectively).

\subsection{Field observations and training samples}

Field surveys were conducted during May-June and September-October 2012 to allow the seasonal match with the satellite image acquisition and to identify and locate selected classes on the ground for collecting ground truth data and training signatures. The one-year interval between remotely-sensed data and field observation is considered sufficiently brief to avoid any misinterpretation (the area is not subject to fire; windfall is minimal, and the rate of expansion of the study species and other alien plants, while yet to be accurately quantified, appears not to be fast enough to bias our interpretation). Thus, based on field investigation, the study determined eight ground cover classes including Albizia adianthifolia, Acacia robusta, Dalbergia obovata, Melia azedarach, Mangifera indica, bare ground and built-up. An additional class simply called "other vegetation" (hereafter other class) typically represented dense vegetation without a peculiar spectral signature. The season and month under consideration enabled us to delineate Melia (in its flowering stage, thereby easily separate associated from other species; Figure 2). As the species is deciduous (leafless in winter, in most cases still leafless when flowering), any point under Melia identified as either Melia or bare ground was considered correctly assigned. 


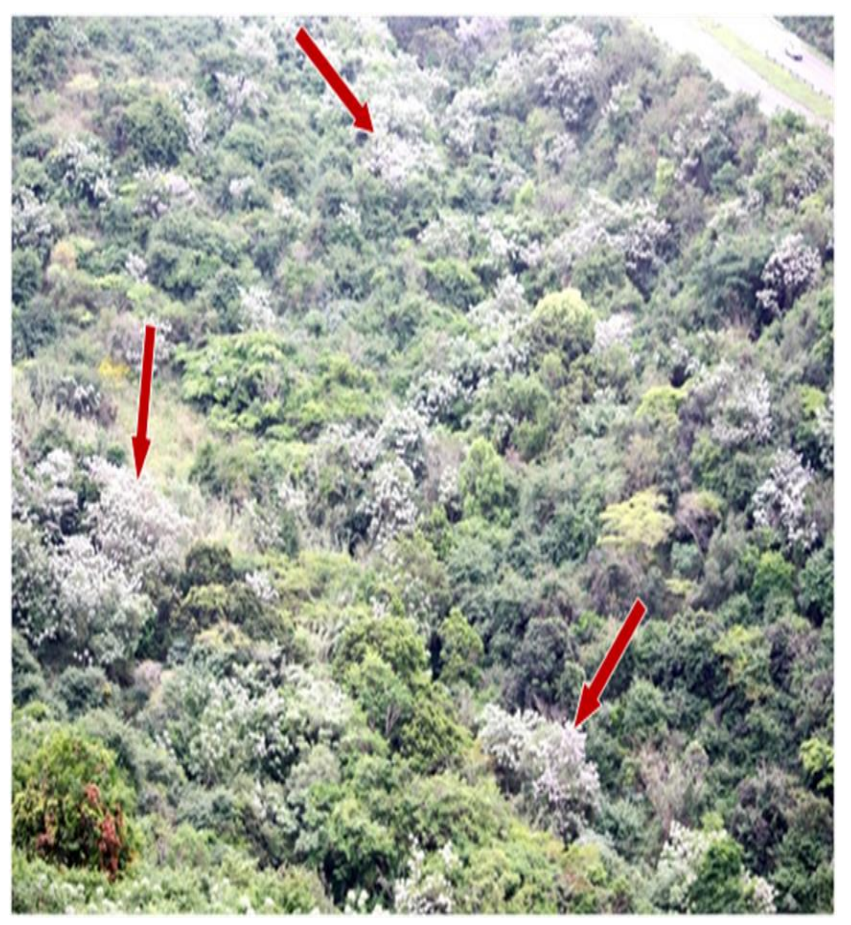

Figure 2. During peak flowering (October 2011), Melia is easily distinguished from surrounding vegetation (numerous trees in photo, a few indicated by arrows).

Firstly we selected training samples spread evenly over the area, corresponding to the classes $A$. adianthifolia, A. robusta, $M$. azedarach, D. obovata, $M$. indica, other, bare ground and built-up areas using a Leica GPS and knowledge of the area. This procedure ensured that the spectral signal in the samples corresponded to the same ground target. Every effort was also made to locate the individual class from the satellite imagery using photographs specifically taken as a visual reference. A true color digital aerial photograph was obtained from eThekwini Municipality which was also used to identify training/test samples. The area was randomly sampled for locating and delineating woody species including Melia and other classes on the composite image. The location of individual classes was recorded and this totaled 120 locations across the study site. Sample size was 30 for Melia, 20 for A. robusta, A. adianthifolia and D. obovata, 15 for $M$. indica, 20 for other class and 5 samples for bare ground and built-up. This information helped in identifying the distinct tone and texture for different classes. The field data was separated randomly within each class as $70 \%$ for training purposes and $30 \%$ for validation. Based on field observation estimates of tree species composition in the overstorey canopy and their density were also made in September-October 2012.

\subsection{Image classification and accuracy assessment}

The WV-2 multispectral image was classified using a conventional pixel-based classification with a maximum likelihood classifier. As a parametric classifier, the maximum likelihood classification 
method (equation 1), calculates the probability that a given pixel belongs to a specific class and assigns the pixel to the class having the highest probability (Richards, 1999). Supervised maximum likelihood classification was conducted in ERDAS Imagine ver. 10.

$\mathrm{P}(\mathrm{i} \mid \varpi)=\mathrm{P}(\Phi \mid \mathrm{i}) \mathrm{P}(\mathrm{i}) / \mathrm{P}(\varpi)$ Equation 1

where: $\mathrm{P}(\bowtie \mid i)$ is the likelihood function, $\mathrm{P}(\mathrm{i})$ is the a priori information, i.e., the probability that class $i$ occurs in the study area and $\mathrm{P}(\Phi)$ is the probability that $\Phi$ is observed. A detailed description of maximum likelihood classifier is available in Ahmad (2012).

Object-based image analysis (OBIA), a classification method that deals with objects (i.e. groups of pixels that are generated by image segmentation) was then performed by segmenting the pansharpened image to meaningful objects. eCognition Professional ver. 8.7 was used for this purpose. Object-based segmentation (Blaschke, 2010) was performed using different scale parameters. By testing different segmentation parameters such as scale, shape/colour, and smoothness/compactness, according to visual comparison and ground-truth and personal knowledge, a set of segmentation parameters were tested until a reasonable segmentation result was achieved and those parameters were selected. Based on the selected parameters, the segmentation was performed. The results from eCognition were classified by an extensive variety of features that include colour, texture, form, and context properties in several forms. This was done using a standard nearest neighbour classifier, which describes the class by user-defined sample objects. A more detailed description of image segmentation and classification is given in Gao et al. (2006). In order to compare the accuracy of the classification result created by the two approaches (i.e. pixel-based and object-oriented), the same set of ground truth data was used and the classification feature created in eCognition was exported into ArcGIS ver. 9.3. Classified images were then cross-validated with the ground-truth map (test area). Correspondence metrics including producer's and user's accuracies, overall classification accuracy, and kappa statistics were calculated for the classification. The accuracy assessment of the two methods was compared using the error or confusion matrix. The error matrix relates the accuracy of the classification on a class to class basis and also provides the accuracy of the classification compared to the reference image.

\section{Results and Discussion}

The classification accuracy for the WV-2 image, classified using a conventional pixel-based classification and object-oriented classification are listed in Table 1.

Table 1. Accuracy assessment results from pixel-based and object-oriented classification. 


\begin{tabular}{lcccccc}
\hline Class name & \multicolumn{2}{c}{ Pixel-based classification } & \multicolumn{2}{c}{ Object-oriented classification } \\
\hline & $\begin{array}{c}\text { Producer's } \\
\text { accuracy } \\
(\boldsymbol{\%})\end{array}$ & $\begin{array}{c}\text { User's } \\
\text { accuracy } \\
(\mathbf{\%})\end{array}$ & $\begin{array}{c}\text { Kappa } \\
\text { Producer's } \\
\text { accuracy } \\
\mathbf{( \% )}\end{array}$ & $\begin{array}{c}\text { User's } \\
\text { accuracy } \\
(\boldsymbol{\%})\end{array}$ & Kappa \\
Melia azaderach & 85.7 & 83.2 & 0.8 & 92.5 & 91 & 0.9 \\
Albizia adianthifolia & 50 & 100 & 1 & 87.5 & 95.4 & 0.9 \\
Mangifera indica & 85.7 & 75 & 0.7 & 92.5 & 88 & 0.8 \\
Acacia robusta & 50 & 100 & 1 & 83 & 95 & 0.9 \\
Dalbergia obovata & 66.7 & 66.7 & 0.6 & 92.5 & 90 & 0.9 \\
Other & 83.3 & 62.5 & 0.5 & 83 & 82 & 0.8 \\
Built-up & 100 & 100 & 1 & 100 & 100 & 1 \\
Bare ground & 100 & 100 & 1 & 100 & 100 & 1 \\
Overall classification accuracy: $78 \%$ & & & Overall classification accuracy: $90 \%$ \\
Overall kappa: 0.7 & & & & Overall kappa: 0.8 & \\
\hline
\end{tabular}

The overall classification accuracies for pixel-based classification and object-oriented classification are $78 \%$ and $90 \%$ respectively. Part of the high classification accuracy appeared to be due to the employment of object-oriented classification method which uses segmentation approach for a better spatial and spectral identification of ground features on a very high spatial resolution imagery. Our results support the statement that object-oriented classification may result in increased accuracy, a more appropriate and realistic representation of the environment (Wicks et al., 2002). Table 1 indeed indicates that in our study object-based approach performed consistently well across all classes, while land cover classes were generally well identified by pixel-based supervised classification (Figure 3). Object-oriented classification provided better results in terms of distinguishing Melia trees (Figure 4). 


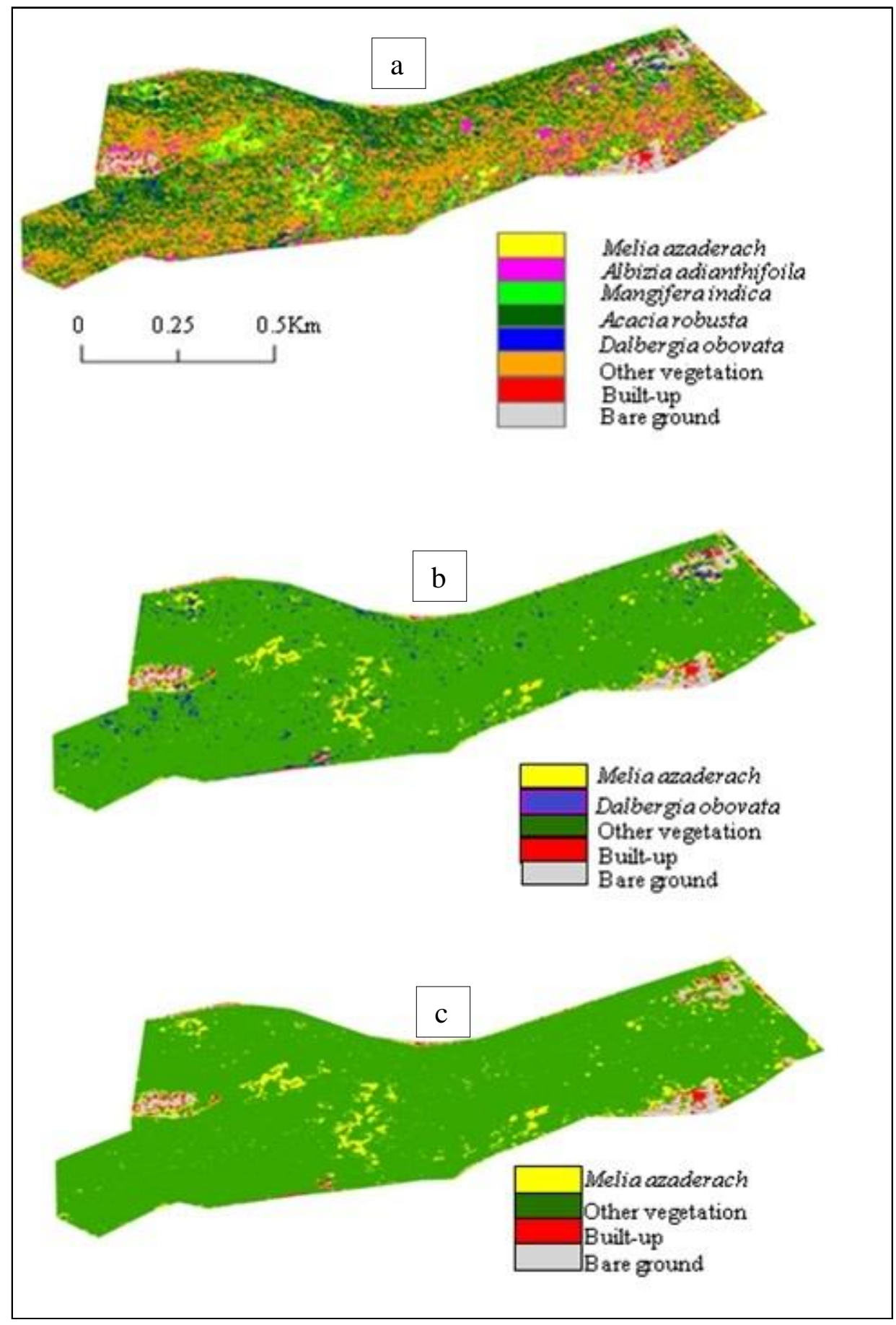

Figure 3. (a) Map produced from the supervised maximum likelihood classification of WV-2 imagery showing all eight classes (b) Target class Melia with indigenous Dalbergia (c) Target class Melia. 


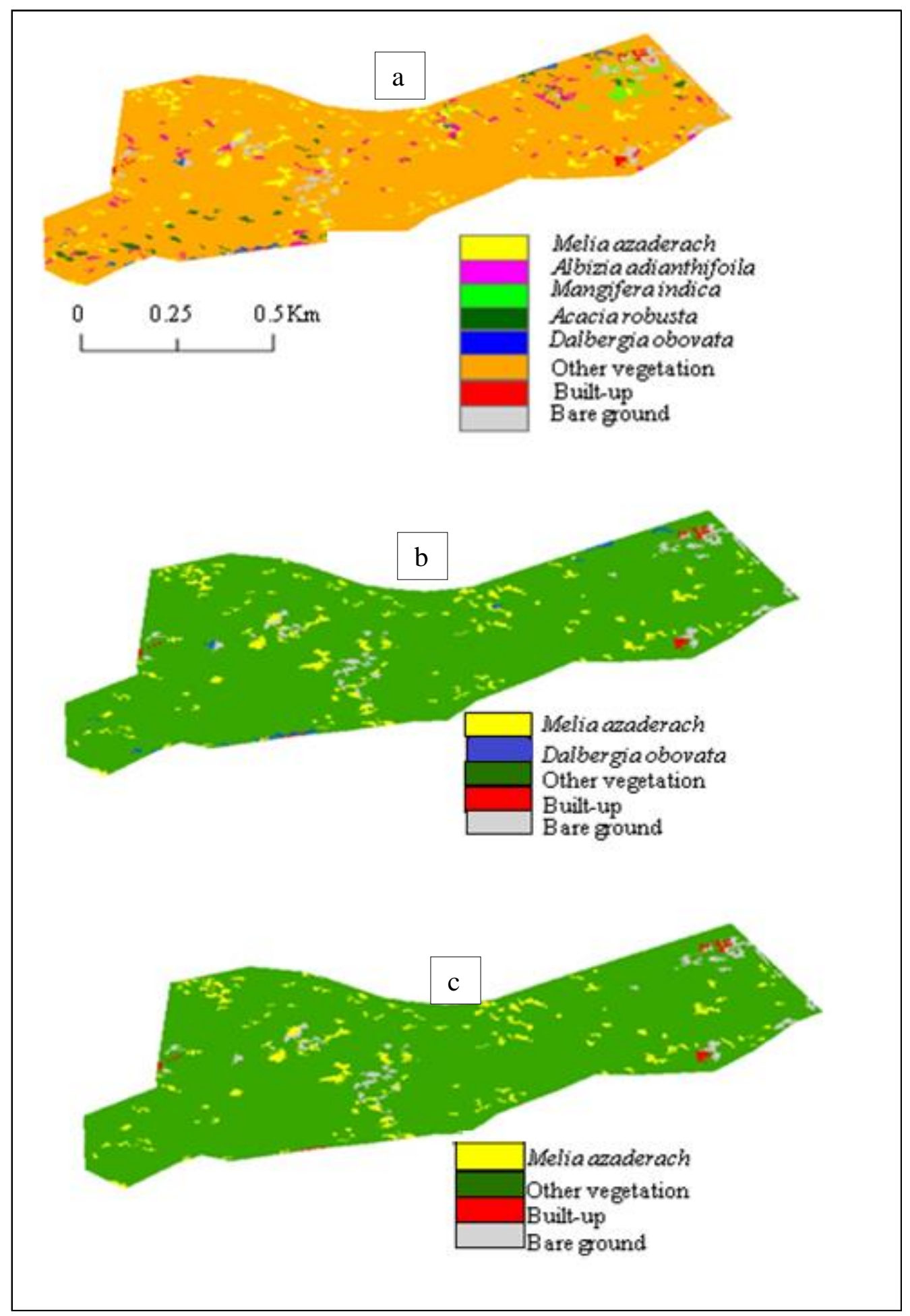

Figure 4. (a) Map produced from the object-oriented classification of WV-2 imagery showing all eight classes (b) Target class Melia with indigenous Dalbergia (c) Target class Melia.

Using pixel-based classification, the target species Melia had a user's accuracy of $85 \%$ and a producer's accuracy of $83 \%$. However, the user's accuracy increased to $91 \%$ with object-oriented classification. Therefore, it can be concluded that the object-oriented classification method performed better in detecting Melia in the study area. Recently, IKONOS imagery has been used for mapping an 
invasive woody plant, Pittosporum undulatum, and authors found that segmentation-based approach was most appropriate to separate this species from other land-cover/vegetation classes (Gil et al., 2013). The object-oriented approach, by contrast, accurately identified such features (Figure 4b). A possible explanation for the confusion of Melia with other classes is that during the months of September and October, the spectral response of bare ground is influenced by the presence of dry grass, matching to some extent Melia flowers.

In the pixel-based classification method producer's accuracies for A. adianthifolia and A. robusta were relatively low $(50 \%)$ due to large variation of spectral signatures. However, the object-oriented classification method worked well in identifying these species with good producer's and user's accuracies. Producer's accuracies of over $65 \%$ were achieved for all classes except for A. adianthifolia and $A$. robusta, which were misclassified most frequently as the common $D$. obovata. The highest user's accuracy was for the A. adianthifolia, A. robusta and M. azedarach classes. In present study only dominant woody species present at the study site was considered and this lowered the possibility of a greater level of spectral overlap to occur between all of the species present. Among the differences that can be observed between Fig. 3a and Fig. 4a, most notably some areas classified as Acacia and Mangifera in the pixel-based classification simply appear as "other vegetation" in the object-oriented classification.

The ability to differentiate invasive species based on remotely sensed data is increased when plants have unique phenological stages relative to the surrounding vegetation (McGowen et al., 2001; Joshi et al., 2004). Some invasive plants flower or green up at a different time compared to the surrounding vegetation. In Idaho, four-band multispectral imagery captured from fixed wing aircraft and with very high spatial resolution that coincided specifically to flowering events aided in the detection of Centaurea solstitalis (Lass et al., 1996). In New Mexico grasslands, Gutierrezia sarothrae was differentiated from surrounding grassland species because of its distinct phenological characteristics (Peters et al., 1992). Similarly, in the present study, Melia was easier to tell apart from other trees because it flowers when most of other trees are not in flowering, although, as mentioned, this caused other cases of misclassification, albeit arguably more limited and easier to correct. In this context, information on the trees' age at first flowering should be factored in for future studies, particularly in cases of rapid range expansion.

The information on the distribution of Melia trees obtained from the interpretation of satellite data in conjunction with ground data can be used to strengthen the ongoing management of the invasive plant species in the study area. As a further research topic, it would be interesting to investigate the improvement in the accuracy of the results of the present study if LIDAR data are also included for canopy structural analysis for Melia. It was assumed that both the higher spatial resolution and the additional spectral bands of WV-2 had improved the classification of target Melia trees. The derived map also provided estimates of woody species composition that showed good agreement with the field-based estimates. As from Table 2, it is evident that the most abundant indigenous woody species 
for the area are A. adianthifolia, A. robusta and D. obovata. The most dominant alien tree species is by far Melia.

In order to use remotely-acquired data in invasion management, the type of analysis performed here would have to ideally be performed across areas, and repeated temporally. Distributional information currently available for alien species, even in the case of woody plants which are relatively well mapped, is often restricted to data at the quarter-degree square scale. Such coarse data, even if regularly updated, could create the impression that the spread of an alien species has slowed down or even stopped, when in fact the species is increasing dramatically in cover at the local scale. Identifying the areas where this is indeed happening could help focus control efforts, and studies such as ours are needed in refining the tools towards species identification.

Table 2. Woody species in the overstorey canopy, their approximate density and Total Basal Area (TBA) in the study area.

\begin{tabular}{|c|c|c|c|c|}
\hline Species & Family & Origin & $\begin{array}{c}\text { Density } \\
\left(\text { ha }^{-1}\right)\end{array}$ & $\begin{array}{l}\text { TBA } \\
\left(\mathrm{m}^{2} \mathrm{ha}^{-1}\right)\end{array}$ \\
\hline Acacia robusta & Fabaceae & Native & ca.40 & 2.43 \\
\hline Acacia nilotica & Fabaceae & Native & ca. 20 & 0.15 \\
\hline Acacia sieberiana & Fabaceae & Native & ca. 10 & 0.05 \\
\hline Albizia adianthifolia & Fabaceae & Native & ca. 50 & 2.36 \\
\hline Bridelia micrantha & Euphorbiaceae & Native & ca. 10 & 1.07 \\
\hline Clerodendron glabrum & Verbenaceae & Native & ca. 10 & 0.08 \\
\hline Combretum molle & Combretaceae & Native & ca. 10 & 2.03 \\
\hline Croton sylvaticus & Euphorbiaceae & Native & ca. 20 & 0.10 \\
\hline Cussonia spicata & Araliaceae & Native & ca. 10 & 0.04 \\
\hline Dalbergia obovata & Fabaceae & Native & ca. 40 & 0.28 \\
\hline Faurea saligna & Proteaceae & Native & ca. 10 & 1.02 \\
\hline Ficus capensis & Moraceae & Native & ca. 10 & 0.03 \\
\hline Ficus natalensis & Moraceae & Native & ca. 10 & 1.05 \\
\hline Heteropyxis natalensis & Heteropyxidaceae & Native & ca. 10 & 0.06 \\
\hline Hippobromus pauciflorus & Sapindaceae & Native & ca. 10 & 0.04 \\
\hline Jacaranda mimosifolia & Bignoniaceae & Tropical America & ca. 10 & 0.08 \\
\hline Litsea glutinosa & Lauraceae & Tropical Asia & ca. 10 & 0.01 \\
\hline Mangifera indica & Anacardiaceae & Tropical Asia & ca. 40 & 5.21 \\
\hline & Meliaceae & Tropical Asia, & & \\
\hline Melia azedarach & & Australia & ca. 120 & 14.98 \\
\hline Protorhus longifolia & Anacardiaceae & Native & ca. 10 & 2.03 \\
\hline Sclerocarya birrea & Anacardiaceae & Native & ca. 10 & 3.02 \\
\hline Searsia chirindensis & Anacardiaceae & Native & ca. 10 & 0.04 \\
\hline \multirow[t]{2}{*}{ Zizyphus mисronata } & Rhamnaceae & Native & ca. 10 & 0.02 \\
\hline & & & & 36.18 \\
\hline Total & & & & \\
\hline
\end{tabular}




\section{Conclusions}

Remote sensing provides a tool for generating important information on distribution of plant species over time which is more cost, labour, and time efficient relative to field based monitoring (Ozesmi \& Bauer, 2002). Such a tool is crucial to successfully discriminate, map and monitor rapidly spreading alien invasive plants such as Melia azedarach.

This study showed the power of WorldView-2 data in individualising tree species at detailed scale. Besides mapping the alien target species, WV-2 imagery is also very useful in the mapping of indigenous tree species. In our study area, taking these efforts further and using different types of imagery, it would be useful to map indigenous trees over larger forest areas. Especially, the scarp forests with their small patch size are rich in flora and fauna, and trees that exhibit their own peculiarities in terms of population structure, growth habit and distribution. These species-diverse scarp forests are being recognized as a diverse habitat of high importance for conservation, sensitive to climate change and habitat fragmentation, but fine-scale information on distributions and patterns of tree species diversity are still lacking. The ability to map a specific tree species over large and diverse areas from remotely sensed imagery would, therefore, be a major step forward in understanding the fine-scale heterogeneity in vegetation, species coexistence and the spatial distribution of tree species diversity.

\section{Acknowledgments}

The authors acknowledge Yadalayan Govinder (Parks, Recreation and Culture Unit, eThekwini Municipality) and Arvind Bhatt for their assistance with collecting field data. SG was supported by a UKZN postdoctoral fellowship, and ŞP's research is funded by National Research Foundation's (South Africa) incentive funding initiative for rated researchers. DR is supported by the EU BON (Building the European Biodiversity Observation Network) project, funded by the European Union under the 7th Framework programme, Contract No. 308454 and by the DIARS FP7 project funded by the European Union.

\section{Conflict of interest}

The authors do not have any actual or potential conflict of interest.

\section{References}

Ahmad A. (2012). Analysis of maximum likelihood classification on multispectral imagery. Applied Mathematical Sciences, 6, 6425-6436.

Arenas-Castro, S., Julien, Y., jiménez-muñoz, J.C., Sobrino, J.A., Fernández- Haeger, J., \& Jordano-Barbudo, D. (2013). Mapping wild pear trees (Pyrus bourgaeana) in Mediterranean forest using high-resolution QuickBird satellite imagery. International Journal of Remote Sensing, 34(9-10), 3376-3396. 
Bernabé, S., Reddy Marpu, P., Plaza, A., Dalla Mura, M., \& Benediktsson, A. (2014). Spectral-spatial classification of multispectral images using kernel feature space representation. I.E.E.E. Geoscience and Remote Sensing Letters, 11, 288-292.

Blaschke, T. (2010). Object Based Image Analysis for Remote Sensing. ISPRS Journal of Photogrammetry and Remote Sensing, 65, 2-16.

Bradley, B.A. \& Mustard, J.F. (2006). Comparison of phenology trends by land cover using remote sensing. Ecological Applications, 16(3), 1132-1147.

Gao, Y., Mas, J. F., Maathuis, B.H.P., Zhang, X. M., \& Van Dijk, P.M. (2006). Comparison of pixel based and object oriented image classification approaches a case study in a coal fire area, Wuda, Inner Mongolia, China. International Journal of Remote Sensing, 27 4039-4051.

Gil, A., Lobo, A., Abadi, M., Silva, L., \& Calado, H. (2013). Mapping invasive woody plants in Azores Protected Areas by using very high-resolution multispectral imagery. European Journal of Remote Sensing, 46, 289-304.

Hantson, W., Kooistra, L., and Slim A. (2012) Mapping invasive woody species in coastal Dunes in the Netherlands: A remote Sensing approach using LiDAR and High-Resolution Aerial photographs. Applied vegetation science, 15:536 - 547

He, K.S., Rocchini, D., Neteler, M., \& Nagendra, H. (2011). Benefits of hyperspectral remote sensing for tracking plant invasions. Diversity and Distributions, 17, 381-392.

Huang, C. \& Asner, G.P. (2009). Applications of remote sensing to alien invasive plant studies. Sensors, 9, 48694889.

Immitzer, M., Atzberger,C., \& Koukal, T. (2012). Suitability of WorldView-2 data for tree species classification with special emphasis on the four new spectral bands. Photogrammetrie Fernerkundung Geoinformation, 5, 573-588.

Joshi, C.M., De Leeuw, J., \& Van Duren, I.C. (2004). Remote sensing and GIS applications for mapping and spatial modelling of invasive species. Proc. XXth ISPRS congress: Geo-imagery bridging continents, Comm. VII, Istanbul, Turkey, 12-23 July 2004, pp. 669-677.

Laba, M., Downs, R., Smith, S., Welsh, S., Neiderc, C., White, S., Richmond, M., Philpot, W., \& Baveye, P. (2008). Mapping invasive wetland plants in the Hudson River National Estuarine Research Reserve using Quickbird satellite imagery. Remote Sensing of Environment, 112(1), 286-300.

Lass, L.W., Carson, H.W., \& Callihan, R.H. (1996). Detection of yellow starthistle (Centaurea solstitialis) and common St. John's wort (Hypericum perforatum) with multispectral digital imagery, Weed Technology, 10, 466-474.

Levin, N., Shmida, A., Levanoni, O., Tamari, H., \& Kark, S. Predicting mountain plant richness and rarity from space using satellite-derived vegetation indices. Diversity and Distributions, 13, 692-703.

Lucas, R., Bunting, P., Paterson, M., \& Chisholm, L. (2008). Classification of Australian forest communities using aerial photography, CASI and HyMap data. Remote Sensing of Environment, 112, 2088-2103. 
Mcgowen, I.J., Frazier, P., \& Orchard, P. (2001). Remote sensing for broad scale weed mapping - is it possible? Proceedings of the 5th Australasian Geospatial Information and Agriculture Conference, Sydney, Australia, 16-19 July 2001, pp. 10-21.

Omar, H. (2010). Commercial timber tree species identification using multispectral Worldview-2 Data. Research report submitted to DigitalGlobe ${ }^{\circledR}$ Incorporated, USA for the WorldView-2, 8-Bands Research Challenge. Longmont, CO: DigitalGlobe ${ }^{\circledR}$.

Ozesmi, S. L., \& Bauer, M. E. (2002). Satellite remote sensing of wetlands. Wetlands Ecology and Management, 10, 381-402.

Peerbhay, K. Y., Mutanga, O., and Ismail, R. (2016). The identification and remote detection of alien invasive plants in commercial forests: An Overview. South African Journal of Geoinformatics, 5-1: $49-67$.

Peters, A. J., Reed, B. C., Eve, M. D., \& Mcdaniel, K. C. (1992). RS of brome snakeweed (Gutierrezia sarothrae) with NOAA-10 spectral image processing. Weed Technology, 6, 1015-1020.

Procheş, Ş., Wilson, J. R. U., Richardson, D. M., \& Rejmánek M. (2012). Native and naturalized range size in Pinus: relative importance of biogeography, introduction effort and species traits. Global Ecology and Biogeography, 21 513-523.

Pyšek, P. \& Richardson, D.M. (2010). Invasive species, environmental change and management, and ecosystem health. Annual Review of Environment and Resources, 35, 25-55.

Qian H, Ricklefs R (2006) The role of exotic species in homogenizing the North American flora. Ecology Letters, 9: 1293-1298.

Richards, J. A. (1999). Remote Sensing Digital Image Analysis: An Introduction. Third Revised and Enlarged Edition, Springer-Verlag, Heidelberg, Germany.Richardson, D. M., Hui, C., Nunez, M. A., Pauchard, A. (2014). Tree invasions: patterns, processes, challenges and opportunities. Biological Invasions 16, 473-481.

Rocchini, D. (2007). Effects of spatial and spectral resolution in estimating ecosystem $\alpha$-diversity by satellite imagery. Remote Sensing of Environment, 111, 423-434.

Rundel, P. W., Dickie, I. A., \& Richardson, D. M. (2014). Tree invasions into treeless areas: mechanisms and ecosystem processes. Biological Invasions 16, 663-675

Stow, D., Hamada, Y., Coulter, L., \& Anguelova, Z. (2008). Monitoring shrubland habitat changes through object-based change identification with airborne multispectral imagery. Remote Sensing of Environment, 112, 1051-1061.

Thuiller, W., Richardson, D. M., Rouget, M., Procheş, Ş., \& Wilson, .J. R. U. (2006). Interactions between environment, species traits, and human uses describe patterns of plant invasions. Ecology 87 1755-1769.

Thuiller, W., Lavorel, S., Araújo, M.B., Sykes, M.T., \& Prentice, I.C. (2007). Climate change threats to plant diversity in Europe. Proceedings of the National Academy of Sciences, 102, 8245-8250.

Voigt, F.A., Farwig, N., \& Johnson, S.D. (2011). Interactions between the invasive tree Melia azedarach (Meliaceae) and native frugivores in South Africa. Journal of Tropical Ecology, 27, 355-363.

Wicks, T., Smith, G., \& Curran, P. (2002). Polygon-based aggregation of remotely sensed data for regional ecological analysis. International Journal of Applied Earth Observation and Geoinformation, 4, 161-173. 
Wilfong, B.N., Gorchov, D.L., \& Henry, M.C. (2009). Detecting an invasive shrub in deciduous forest understories using remote sensing. Weed Science, 57, 512-520. 